\title{
A IMPORTÂNCIA DOS ESPAÇOS PÚBLICOS DE PARTICIPAÇÃO POLÍTICA E INSTITUCIONAIS PARA CONQUISTA E EFETIVIDADE DOS DIREITOS QUILOMBOLAS POSITIVADOS POR MEIO DA CONSTITUIÇÃO DO BRASIL DE 1988
}

\author{
Fábio Eduardo Biazon Abrantes* \\ Kathleen Cristina Tie Scalassara** \\ Marlene Kempfer
}

\begin{abstract}
Resumo:
Trata-se de pesquisa acadêmica de revisão bibliográfica, documental, e indutiva, para investigar e aferir a importância dos espaços públicos de participação política, bem como de tutela jurídica institucional para a conquista e efetividade dos Direitos Quilombolas, positivados por meio da Constituição 1988. Dentre tais direitos enfatizam-se os de natureza cultural imaterial quilombolas para titulação pelo Instituto do Patrimônio Histórico e Artístico Nacional (IPHAN) e aqueles para a titulação da propriedade quilombola e direitos dela decorrentes.

Palavras-chave: Comunidades Quilombolas; Participação Política; Movimentos Sociais; Efetividade de Direitos; Patrimônio Cultural.

\section{THE IMPORTANCE OF PUBLIC SPACES FOR POLITICAL AND INSTITUTIONAL PARTICIPATION TO ACHIEVE AND EFFECTIVENESS OF THE QUILOMBOL RIGHTS POSITIVE THROUGH THE CONSTITUTION OF BRAZIL 1988}

\begin{abstract}
:
This is academic research of bibliographic, documentary and inductive revision, to investigate and assess the importance of public spaces for political participation, as well as institutional legal protection for the conquest and effectiveness of Quilombola Rights, made positive through the 1988 Constitution. Among these rights, those of quilombola material and immaterial cultural nature are emphasized for titling by the Instituto do Patrimônio Histórico e Artístico Nacional (IPHAN) and those for the titling of quilombola property and the rights arising therefrom.

Keywords: Quilombola Communities; Political Participation; Social movements; Effectiveness of Rights; Cultural heritage

\section{INTRODUÇÃO}

\footnotetext{
* Mestrando em Direito Negocial, especialista em direito do estado, com ênfase em tributário, graduado em Direito, todos pela Universidade Estadual de Londrina (UEL). Vinculado ao projeto de pesquisa: Intervenção do Estado sobre o domínio econômico em face da Constituição Federal de 1988: possibilidades de reconfiguração das relações entre Estado e Mercado. Endereço eletrônico: fabio.abrantes@uel.br.

** Mestranda em Direito Negocial pela Universidade Estadual de Londrina (UEL), MBA em Gestão e Business Law pela Fundação Getúlio Vargas (FGV), graduada em Direito pela Universidade Estadual de Londrina (UEL). Vinculada ao projeto de pesquisa: Intervenção do Estado sobre o domínio econômico em face da Constituição Federal de 1988: possibilidades de reconfiguração das relações entre Estado e Mercado. Endereço eletrônico: kathleen.tie.scalassara@uel.br.

${ }_{* * * *}^{\text {*** }}$ Doutora e Mestre em Direito do Estado pela Pontifícia Universidade Católica de São Paulo (PUC/SP). Professora da graduação em Direito e do Programa de Mestrado em Direito Negocial da Universidade Estadual de Londrina. Endereço eletrônico: mkempferb@gmail.com.
} 
São fundamentais os movimentos sociais tanto aqueles que recorrem a articulações discursivas quanto aqueles que lutam nas instituições públicas para buscar efetividade práticas das reivindicações. Estes espaços públicos, defendidos pelo ideário republicano, possibilitam reconhecimento, autonomia e emancipação, dos indivíduos ou de suas comunidades.

Neste sentido a presente pesquisa, de natureza documental e revisão bibliográfica, revela a luta dos negros brasileiros por meio de movimentos ou lutas discursivas individuas e comunitárias, que buscam reconhecimento de suas identidades refletidos em seu precioso patrimônio cultural material e imaterial, e nos espaços geográficos que são identificados de terras quilombolas.

Os resultados destas lutas foram positivados, e estão registrados na Constituição da República Federal do Brasil de 1 988. Quanto ao reconhecimento cultural nos art. 215, § $1^{\circ}$, de forma originária e art. 215, inciso V, incluído pela Emenda Constitucional n. 48/2005. Com previsão de tombamento dos documentos e sítios detentores de reminiscências históricas dos antigos quilombos no art. $216, \S 5^{\circ}$. E quanto ao direito às terras quilombolas no art. 68 do Ato das Disposições Constitucionais Transitórias - ADCT.

Felizmente, no ano de 2013, foram realizadas pesquisas pelo Laboratório de História Oral e Imagem (LABHOI) da Universidade Federal Fluminense, e pelo Instituto Socioambiental (ISA) e, assim, tem-se, atualmente, registros sobre manifestações dos descentes, em territórios quilombolas identificados, daqueles que por causa da Diáspora Africana foram arrancados de suas raízes, mas, que não desistiram de alimentar suas identidades na nova terra Brasil. Estes documentos possibilitam apontar algumas importantes manifestações culturais materiais e imateriais em territórios quilombolas.

Para esta pesquisa, aponta-se registros que estão no "Inventário dos Lugares de Memória do Tráfico Atlântico de Escravos e da História dos Africanos Escravizados no Brasil”, e no "Inventário Cultural Quilombola do Vale do Ribeira", região de grande concentração quilombola, entre os estados de São Paulo e Paraná, com dados fortemente representativos das manifestações de outros territórios quilombolas brasileiros.

Estes preciosos registros conferem visibilidade a estas culturas e, assim, confirma-se a legitimidade das lutas que conseguiram constitucionalizar este patrimônio, elevando-os à condição de direitos que devem compor políticas do Estado brasileiro. Na condição de direitos constitucionais segue-se nova etapa de luta. Agora, junto as instituições estatais para alcançar a efetividade. O destaque para este artigo são as conquistas junto ao Judiciário brasileiro em 
diversas temáticas de acesso: à titulação das terras, à moradia digna, à intributabilidade de suas terras e prioridade no Plano Nacional de Operacionalização da Vacinação contra COVID-19.

\section{ESPAÇOS PÚBLICOS DE PARTICIPAÇÃO POLÍTICA PARA CONQUISTA DE DIREITOS QUILOMBOLAS}

A concepção do Brasil enquanto Estado é consideravelmente recente, em perspectiva aos demais Estados do mundo, haja vista que o lapso temporal entre o início do processo de colonização e a contemporaneidade dos dias hodiernos é pouco mais de 500 anos. Durante esse lapso temporal, por quase 400 anos, teve-se como base da economia a exploração da mão de obra escravizada, proveniente do tráfico humano dos povos pretos de diversas regiões do continente Africano, que foram abruptamente desenraizados de sua cultura e costumes nativos, reduzidos à propriedade de outrem, evento também conhecido como Diáspora Africana.

Para Lourival Vilanova (2000, p. 255) "há Estado se uma coletividade estabiliza-se espacialmente e se provê de indivíduo-órgão para o exercício de Poder", considerando a multiplicidade do pluralismo dos grupos de indivíduos dispersos na sociedade pré-estatal, internamente polisseguimentada, que confluem para unificação "não apenas por um fator naturalístico (raça, religião), mas enquanto tal fator sirva de substrato a uma norma de organização (instituidora do órgão)" (2000, p. 255-257), formalmente instituído no Brasil por meio de sua primeira Constituição, outorgada em 1824.

A Carta de Lei de 25 de março de 1824 tratava da Constituição Política do Império do Brasil, elaborada por um Conselho de Estado e outorgada pelo Imperador D. Pedro I, em 25 de março de 1824, bem como de questões do Império do Brasil, entre elas a definição de cidadãos brasileiros contida no Art. 6, inciso I, como "Os que no Brazil tiverem nascido, quer sejam ingenuos, ou libertos, ainda que o pai seja estrangeiro, uma vez que este não resida por serviço de sua Nação", desconsiderando-se completamente a existência do grupo de seres humanos escravizados, reduzidos ao regime jurídico de propriedade e sujeitos à comercialização.

Teixeira de Freitas (2003, p. 146) classificou as pessoas escravizadas como bens móveis, acessórios às terras negociadas, tal qual os semoventes, e conceituou o estado de escravidão como oposto à liberdade, posteriormente conquistada por pressões sociais, e formalmente sancionada pela Lei 3.353 de 13 de maio de 1888. A Lei Áurea declarou extinta a escravidão no Brasil, sem previsão de qualquer projeto emancipatório, indenizatório ou de 
integração dos seres humanos que, por quase quatro séculos, tiveram sua humanidade retirada.

A ausência de Políticas Públicas para garantia da dignidade das pessoas recém-libertas, inviabilizou o efetivo exercício e fruição da liberdade recém conquistada, portanto "sem as condições adequadas para o uso da liberdade, qual é o valor da liberdade?” (BERLIN, 2002, p. 138). A percepção de valor pode ser aferida em contraponto da satisfação de necessidades, segundo Johannes Hessen "será valor tudo aquilo que for apropriado a satisfazer determinadas necessidades humanas" (1964, p. 41-42), portanto, a sanção da Lei Áurea não foi capaz de satisfazer as necessidades das pessoas por efetiva liberdade.

Com efeito, o próprio conceito de liberdade sofreu alterações durante o transcurso do tempo, em decorrência da dinâmica da vida e cultura das sociedades, com significados distintos, conforme os diferentes períodos da civilização. Para os antigos, a liberdade era concebida como "a partilha do poder social entre todos os cidadãos de uma mesma pátria" (CONSTANT, 1985, p. 15), e para os modernos, a liberdade "é a segurança dos privilégios privados" (CONSTANT, 1985, p. 10), cujo perigo reside na renúncia da participação do poder político, que pode levar ao encolhimento do espaço público de participação na política.

O Brasil passou a adotar a República enquanto regime de governo, em 24 de fevereiro de 1891, quando foi promulgada a Constituição da República dos Estados Unidos do Brasil, teoricamente pelos representantes do povo brasileiro, reunidos em Congresso Constituinte, para organizar um regime livre e democrático. No entanto, promulgou-se a Constituição sem qualquer diálogo com o grupo remanescente da Diáspora Africana, que a essa altura já eram cidadãos integrantes da sociedade.

Para Renato Janine Ribeiro (2005, p. 34):

República é um conceito romano, como democracia é um termo grego. Vem de res publica, coisa pública. Surgiu em Roma substituindo a monarquia, mas monarquia e república não se definem pelo mesmo critério. Monarquia se define por quem manda: significa o poder (arquia) de um (mono) só. Já a palavra república não indica quem manda, e sim para que manda. O poder aqui está a serviço do bem comum, da coisa coletiva ou pública. Ao contrário de outros regimes, e em especial da monarquia, na república não se busca a vantagem de um ou de poucos, mas a do coletivo.

A concepção de liberdade para a tradição republicana pode ser observada pelo conceito formulado por Philip Pettit, no sentido romano, para o qual "a liberdade é tomada no sentido de não-dominação, e não de não-interferência" (1999, p. 52, tradução livre) e principalmente pelo pensamento de Hannah Arendt, para a qual:

A coisa política entendida nesse sentido grego está, portanto, centrada em torno da liberdade, sendo liberdade entendida negativamente como o não-ser-dominado e nãodominar, e positivamente como um espaço que só pode ser produzido por muitos, 
onde cada qual se move entre iguais. Sem esses outros que são meus iguais não existe liberdade alguma. (ARENDT, 2002, p. 48).

A primeira Constituição Republicana do Brasil sequer previu expressamente a igualdade formal, demonstrando a ausência de liberdade no sentido positivo em Arendt, uma vez que não havia o espaço movido entre iguais, uma vez que permanecia o projeto de dominação pela raça:

\begin{abstract}
Naquele momento, os projetos emancipacionistas não excluíam a construção de novas formas de dominação fundamentadas na noção de raça. Mesmo porque o que se via eram tentativas cada vez mais incisivas de adaptar à sociedade pós abolição as hierarquias raciais montadas durante a escravidão. Pensar o mundo republicano e sem escravidão não queria dizer pensar uma sociedade de oportunidades iguais; muito pelo contrário, a preocupação estava em garantir que brancos e negros continuariam sendo não só diferentes, mas desiguais. (ALBUQUERQUE, 2006, p. 205)
\end{abstract}

A liberdade no sentido de não-dominação ou não-interferência não era uma possibilidade para o grupo de ex-escravizados no período pós-abolição, uma vez que a elite branca insistia na tentativa de garantir as desigualdades, de modo que a liberdade de que necessitavam era concebida em seu sentido positivo, para participação na esfera pública para a luta antirracista, possibilitada pela Emenda Constitucional de 3 de setembro de 1926, com o acréscimo do $\S 2^{\circ}$ do Art. 72, onde previa que "Todos são iguaes perante a lei.".

As reivindicações da comunidade negra passaram a ser veiculadas por jornais escritos por negros e para os negros, dando origem a Imprensa Negra, por meio de periódicos destinados a organizá-los em comunidade, denunciar as discriminações e desrespeitos que sofriam, para contribuição na criação de um ambiente favorável à constituição de uma instituição negra nacional, nos moldes dos partidos políticos, com pretensões eleitorais: a Frente Negra Brasileira, criada em 1931, para reivindicar os direitos de seu grupo social:

\footnotetext{
defendendo que a abolição tinha sido "um processo inacabado", que o estado brasileiro tinha uma "dívida" a ser redimida. A idéia de uma "reparação" era apresentada como uma necessidade histórica. Essa dívida apresentava duas dimensões: aquela dos senhores que, ao longo dos séculos, se tinham beneficiado gratuitamente do trabalho escravo, e aquela que perdurava ainda, apesar da igualdade formal garantida pelo ordenamento jurídico, que era o estigma de ser negro, fato que gerava novas situações de exclusão. A luta anti-racista levava à necessidade de elaboração de políticas de reparação. (TRECANI, 2005, p. 97)
}

A Frente Negra Brasileira, constituiu-se durante o período da Primeira República, mas sucumbiu a "repressão e violência impostas pelo Estado Novo", que "fizeram com que o grupo da Frente se dispersasse de fato, sem deixar vestígios" (OLIVEIRA, 2002, p. 90). E o 
Deficitário Regime de Governo Republicano no Brasil perdura há mais de 130 (cento e trinta), enquanto a democracia, com eleições livres e abertura para participação na esfera pública foi exceção, considerando os regimes autoritários do Estado Novo de 1937 a 1945 e do Regime Militar de 1964 a 1985, momento em que repeliu-se toda e qualquer iniciativa reivindicatória de direitos pelo movimento negro, percebidas como ameaça.

Ademais, a República associada à democracia, por si só não garante a criação de novos direitos ou proteção de minorias, contudo, disponibiliza espaços para a construção do debate público, bem como para o exercício da liberdade para a mobilização social e ocupação da esfera pública, pois "pode ser que, sem a pressão de forças sociais, as ideais políticas morram no nascedouro" (BERLIN, 2002, p. 134). E o movimento negro, tão repelido pelos regimes autoritários, fez bom proveito dos espaços públicos de participação política.

Isso porque com a queda do regime militar e início do processo de redemocratização do Brasil, foi instaurada a Assembleia Nacional Constituinte em 1987, com articulação do movimento negro na luta quilombola por reconhecimento, haja vista a incompatibilidade jurídica da organização com o sistema reproduzido na época:

Os quilombos representam uma experiência de ruptura da ordem jurídica vigente na
época. Eram uma constante ameaça à economia colonial, cujo combate exigia a
criação de todo um aparato repressivo especializado. Sua existência durante todo o
regime colonial e imperial, representou a desmoralização do aparato jurídico-
ideológico instalado para combatê-los. (TRECANI, 2005, p. 46)

Os Instrumentos de participação popular política disponibilizados no processo de redemocratização da sociedade brasileira, permitiram ao Movimento Negro a apresentação de suas demandas reivindicatórias, entre elas as questões afetas às comunidades quilombolas, em debates públicos na Assembleia Nacional Constituinte, com a proposta de Emenda de iniciativa popular, posteriormente formalizada pelo Constituinte Carlos Aberto Caó (PDT), em 10 de agosto de 1987, que submeteu as emendas PE00104-7 e 1P20773-8 à apreciação do Plenário, para acrescentá-las ao Título X, das disposições transitórias:

Art. - Fica declarada a propriedade definitiva das terras ocupadas pelas comunidades negras remanescentes de quilombos, devendo o Estado emitir-lhes os títulos respectivos. Ficar tombadas essas terras bem como os documentos referentes à história dos Quilombos no Brasil.

A redação da proposta foi alterada posteriormente, com fragmentação em duas partes, que culminou na inclusão em seções distintas da Constituição. A primeira parte resultou no Art. 68 no ADCT, sobre o reconhecimento e titulação de terras quilombolas, e a segunda parte 
resultou no Art. 216, $\S 5^{\circ}$ da $\mathrm{CF}$, sobre tombamento de documentos e sítios dos antigos quilombos, que entraram em vigor em 03 de outubro de 19998, com a promulgação da sétima Constituição da República Federativa do Brasil.

Assim, pela primeira vez desde de 1824, quando o Brasil se tornou Estado relativamente independente de Portugal, as pessoas pretas remanescentes da Diáspora Africana e organizadas em Comunidades Quilombolas, foram consideradas como cidadãos efetivamente integrantes da sociedade, com a possibilidade de ocupação de espaços públicos de debates e participação política, pela abertura democrática e republicana, que ainda nos dias atuais viabilizam a mobilização social para novas conquistas de Direitos Quilombolas.

Neste sentido, criou-se a Coordenação Nacional de Articulação das Comunidades Negras Rurais e Quilombolas - CONAQ, organização não governamental, sem fins lucrativos e econômicos partidário, fundada em 12 de maio de 1996, em Bom Jesus da Lapa - Bahia, com prazo de duração indeterminado, após a realização da reunião de avaliação do I Encontro Nacional de Quilombos, com objetivos definidos a partir do Art. $3^{\circ}$ de seu Regimento Interno:

Art. $3^{\circ}$ - A CONAQ tem como objetivo lutar pela garantia de uso coletivo do território quilombola, propor o desenvolvimento sustentável de políticas públicas culturais, econômicas, direitos humanos, levando em consideração as organizações existentes nas comunidades quilombolas nos estados brasileiros. (CONAQ, 2013, p. 3)

A CONAQ, enquanto movimento social, surge "não só para reivindicar soluções dos problemas nacionais, mas como também movimento político organizado para alterar as relações desiguais historicamente estabelecidas, em defesa dos direitos das comunidades quilombolas" (CONAQ, 2013, p. 4), anteriormente invisibilizadas e silenciadas pelo Estado, e agora possui instrumentos de participação popular e controle social.

\section{DIREITOS QUILOMBOLAS POSITIVADOS POR MEIO DA CONSTITUIÇÃO DA REPÚBLICA FEDERATIVA DO BRASIL DE 1988}

Os Direitos Quilombolas conquistados nos espaços de participação política positivados por meio da Constituição da República Federativa do Brasil, abrangem questões jurídicas diversas e interdisciplinares, afetas à Proteção da Identidade e Cultura, especificamente positivados no Art. $215, \S 1^{\circ}, 216, \S 5^{\circ}$ da Constituição Federal, bem como ao Reconhecimento e Tutela Jurídica Territorial, positivados no Art. 68 do Ato das Disposições Constitucionais Transitórias - ADCT:

Revista de de Movimentos Sociais e Conflitos | e-ISSN: 2525-9830 | Encontro Virtual | v. 7 | n. 1 | p. $41-61$ | Jan/Jul. 2021. 
Art. 215. O Estado garantirá a todos o pleno exercício dos direitos culturais e acesso às fontes da cultura nacional, e apoiará e incentivará a valorização e a difusão das manifestações culturais.

$\S 1^{\circ} \mathrm{O}$ Estado protegerá as manifestações das culturas populares, indígenas e afrobrasileiras, e das de outros grupos participantes do processo civilizatório nacional.

(...)

Art. 216. Constituem patrimônio cultural brasileiro os bens de natureza material e imaterial, tomados individualmente ou em conjunto, portadores de referência à identidade, à ação, à memória dos diferentes grupos formadores da sociedade brasileira, nos quais se incluem:

$[\ldots]$

$\S 5^{\circ}$ Ficam tombados todos os documentos e os sítios detentores de reminiscências históricas dos antigos quilombos.

(...)

Art. 68. Aos remanescentes das comunidades dos quilombos que estejam ocupando suas terras é reconhecida a propriedade definitiva, devendo o Estado emitir-lhes os títulos respectivos.

A positivação desses Direitos foi um importante passo na luta negra e quilombola, mas sua efetividade revelou-se aquém do esperado. Com importantes denúncias pelo movimento negro quilombola, com diversas iniciativas, sendo restrito para efeitos do presente estudo, na figura das Associações das Comunidades Quilombolas em nível regional e na CONAQ, em nível nacional. As entidades da sociedade civil parceiras das comunidades quilombolas, e consideradas para a presente pesquisa são a Comissão Pró-Índio de São Paulo - CPISP, Terra de Direitos e Instituto Socioambiental - ISA.

As lutas discursivas individuais ou comunitárias, de cunho acadêmico e informativo, também são importantes fontes de pesquisa e difusão para o conhecimento dos Direitos Quilombolas e suas problemáticas, enfatizados os de natureza cultural material e imaterial e aqueles para a titulação de propriedade definitiva quilombola, e os direitos dela decorrentes, na consecução das atividades atribuídas pelo Estado aos órgãos designados para o cumprimento dos direitos positivados.

\subsection{DIREITOS CULTURAIS QUILOMBOLAS}

A Proteção dos Direitos Culturais das Comunidades Quilombolas, enquanto grupo formador da sociedade brasileira, e de manifestações afro-brasileiras, foi positivada no Art. 215, $\S 1^{\circ}$ pelo Constituinte original, de maneira geral, para garantir, apoiar e incentivar o pleno exercício dos direitos culturais e manifestações afro-brasileiras, sem especificá-las ou restringi- 
las, considerando a extensa área territorial do Brasil, onde cada comunidade quilombola pode expressar suas próprias tradições, seus costumes, sua cultura local e se manifestar de forma única, embora relacionada em aspectos comuns às demais comunidades.

O Instituto do Patrimônio Histórico e Artístico Nacional (IPHAN) foi criado pelo Decreto-Lei n. 25 de 30 de novembro de 1937, pelo Chefe do Poder Executivo da época, o Presidente Getúlio Vargas. A partir do referido decreto organizou-se a forma de proteção e constituição do patrimônio histórico e artístico nacional, bem como institui-se o tombamento ${ }^{1}$, com previsão de quatro livros do Tombo: (1) Tombo Arqueológico, Etnográfico e Paisagístico - categoria de bens de arte arqueológica, etnográfica, ameríndia e popular; (2) Tombo Histórico

\footnotetext{
${ }^{1}$ A palavra tombamento originou-se do verbo tombar que - no Direito, em Portugal - tem o sentido de registrar, inventariar, arrolar e inscrever bens. O inventário era inscrito em livro próprio que era guardado na Torre do Tombo, em Lisboa. O termo passou a ser utilizado no Direito brasileiro para designar os bens registrados e tutelados pelo poder público. Disponível em: 〈http://portal.iphan.gov.br/perguntasFrequentes?categoria=9>
}

- categoria das coisas de interesse histórico e obras de arte históricas; (3) Tombo das Belas Artes - categoria das coisas de arte erudita, nacional ou estrangeira; (4) Livro do Tombo das Artes Aplicadas - categoria das artes aplicadas nacionais ou estrangeiras.

Em que pese a previsão de tombamento dos documentos e sítios detentores de reminiscências históricas dos antigos quilombos no Art. $215, \S 5^{\circ}$ da Constituição Federal, ainda não há regulamentação específica para tanto, mesmo após mais de 30 (trinta anos). O tombamento das comunidades quilombolas é praticamente inviabilizado por impasses normativos da regulamentação do tombamento geral, e por conceitos ultrapassados do que são as comunidades quilombolas. Segundo Beatriz Accioly Vaz (2014, p. 80)

\footnotetext{
É sintomático dessa situação o fato de apenas dois quilombos, não mais ocupados por quilombolas, terem sido tombados até hoje - dentre os doze processos já abertos no Iphan para tombamento de quilombos - a Serra da Barriga, antigo Quilombo dos Palmares, e os "Remanescentes do antigo Quilombo do Ambrósio", não ocupados atualmente por populações que se reconhecem como quilombolas, ou remanescentes de quilombo, mas territórios historicamente consagrados como lugares em que existiram quilombos, na concepção mais restrita do termo.
}

Os doze processos em andamento disponibilizados por tabela ${ }^{2}$ confeccionada pelo IPHAN do período de 1938 a 2019, são referentes aos quilombos de: (1) Sacutiaba - em Wanderley (BA); (2) Vão do Moleque - em Cavalcante (GO); (3) Flexal - em Mirinzal (MA); (4) Jamary dos Pretos - em Turiaçu (MA); (5) Porto Coris - em Leme do Prado (MG); (6) Oriximiná - em Oriximiná (PA); (7) Castainho - em Garanhuns (PE); (8) Campinho da 
Independência - em Paraty (RJ); (9) Morro Alto - em Morro Alto (RS); (10) Rincão dos Negros - em Rio Pardo (RS); (11) Mocambo - em Porto da Folha (SE); e (12) Ivaporunduva - em Eldorado (SP).

Assim, sem o tombamento das comunidades quilombolas atuais, vivas, dinâmicas e ricas culturalmente, há o risco de perecimento da própria cultura e identidade quilombola com o transcurso do tempo, pois embora haja a possibilidade de submissão de dossiê fundamentado pleiteando o tombamento de comunidade quilombola, não há qualquer garantia de efetividade da previsão constitucional.

A Lei n. 7.668, de 22 de agosto de 1988, autorizou o Poder Executivo a constituir a Fundação Cultural Palmares (FCP), cuja finalidade originária, entre outras funções, é de promover a preservação dos valores culturais, sociais e econômicos decorrentes da influência negra na formação da sociedade brasileira. A atribuição de identificar, reconhecer os remanescentes das comunidades dos quilombos, e proceder à delimitação e à demarcação das

\footnotetext{
${ }^{2}$ Disponivel em: <http://portal.iphan.gov.br/pagina/detalhes/126> terras por eles ocupadas, e conferir a titulação correspondente, foi acrescentada pela medida provisória n. 2.216-37 de 31 de agosto de 2001.
}

A Fundação Cultural Palmares mapeou $3.524^{3}$ (três mil, quinhentos e vinte e quatro) comunidades quilombolas, mas reconhece que o número total de comunidades pode chegar a 5.000 (cinco mil). Deste modo, o número de comunidades quilombolas existentes no Brasil é muito superior ao número de processos de tombamento em andamento, demonstrando o abismo entre a previsão normativa e a efetividade do Direito.

Com efeito, entre as comunidades quilombolas com processo de tombamento em aberto, destaca-se a de Ivaporunduva, localizada na Região do Vale do Ribeira, com densa concentração de comunidades quilombolas, e considerado um dos mais importantes corredores socioambientais do País, situado entre duas grandes metrópoles brasileiras - São Paulo e Curitiba e concentra o maior número de quilombos do Estado de São Paulo.

Em 2013, o Instituto Socioambiental (ISA) publicou o "Inventário Cultural de Quilombos do Vale do Ribeira"4, um estudo realizado junto às comunidades quilombolas. Neste documento foram identificados 180 bens culturais imateriais pela metodologia do Inventário Nacional de Referências Culturais - INRC-IPHAN, em 16 (dezesseis) quilombos da região, 
durante três anos de trabalho de campo, que culminou no catálogo de cinco categorias de bens culturais: (1) Celebrações, (2) Formas de Expressão, (3) Ofícios e Modos de Fazer, (4) Lugares e (5) Edificações.

As $29^{5}$ (vinte e nove) celebrações identificadas no Inventário Cultural demonstraram a forte relação das Comunidades Quilombolas do Vale do Ribeira com a religião cristã, mais precisamente de origem católica, na medida em que a maioria é relacionada aos Santos e tradições católicas. Para Andrade e Tatto (2013, p. 15) as celebrações quilombolas no vale do Ribeira são como "momentos de suspensão da vida cotidiana em que se atualizam as trocas de

\footnotetext{
${ }^{3}$ Disponível em: <http://www.palmares.gov.br/?p=3041>

4 Disponível em: <https://acervo.socioambiental.org/sites/default/files/publications/pdf-publicacaofinal_inventario.pdf>

${ }^{5}$ 1. Bandeira do Divino; 2. Bom Jesus; 3. Celebrações Espirituais; 4. Entruído/Carnaval; 5. Festa da Associação; 6. Festa da Ostra; 7. Finados; 8. Folia de Reis; 9. Natal; 10. Nossa Senhora Aparecida; 11. Nossa Senhora das Neves; 12. Nossa Senhora do Rosário dos Homens Pretos; 13. Oração de 25 de Março; 14. Recomendação das Almas; 15. Reza de Todos os Santos; 16. Romaria e Coroação de Nossa Senhora; 17. Santa Catarina; 18. Santa Cruz; 19. Santa Luzia; 20. Santo Antônio; 21. São Benedito; 22. São João; 23 São José; 24. São Miguel Arcanjo; 25. São Pedro; 26. São Roque; 27. São Sebastião; 28. São Vicente de Paula; 29. Via Sacra da Quaresma. (ISA, 2013, p. 15)
}

bens simbólicos e há espaço para a diversão e convivência espontânea dentro do sítio". As celebrações também são espaços de participação da comunidade e reafirmação da tradição.

As $24^{6}$ (vinte e quatro) Formas de Expressão identificadas no inventário cultural incluem danças, canções e literatura oral (contos, causos, mitos e lendas). Tratam-se dos bens culturais imateriais mais ameaçados pelas mudanças, segundo o mapeamento do desparecimento da Romaria de São Gonçalo nas comunidades de Eldorado, Iguape e Cananéia e sua integridade em duas comunidades de Iporanga, Porto Velho e Praia Grande (ANDRADE e TATTO, 2013, p. 16). Assim, o estudo realizado pelo ISA, confirma a necessidade urgente de proteção e preservação da cultura quilombola, para que não se esvaia no transcurso do tempo.

A categoria dos ofícios e modos de fazer contém $23^{7}$ (vinte e três) bens imateriais catalogados, incluídos os conhecimentos e práticas utilizados pelos quilombolas em seu cotidiano, seja no desenvolvimento das atividades laborativas agrícolas, nas organizações coletivas de eventos de formas de expressão e celebrações, seja no processamento dos alimentos, da caça, pesca e fabricação de artefatos ou artesanatos de uso doméstico.

Os Lugares catalogados no Inventário Cultural somam $75^{8}$ (setenta e cinco) bens culturais, intrinsecamente relacionados à história de resistência à opressão do regime 


\begin{abstract}
${ }^{6}$ 1. Baile / Faxineira / Forró / Fandango (Festa); 2. Cana Verde; 3. Capoeira; 4. Cavalinho; 5. Celebração Afro; 6. Congada de São Benedito; 7. Cobra Verde ou Cobrinha; 8. Dai-Mão; 9. Dança do Chapéu; 10. Fandango Batido / Nhá Maruca / Recortado; 11. Forró ou Rastapé; 12. Graciana; 13. Hinos Espíritas; 14. Incelências e guardação; 15. Literatura Oral; 16. Macacada e Monada; 17. Marzuca; 18. Mão Esquerda; 19. Mesada dos Anjos; 20. Rancheira; 21. Roda de cantoria; 22. Romaria de São Gonçalo; 23. Terço Cantado; 24. Xote Balanceado. (ISA, 2013, p. 16)

${ }^{7}$ 1. Brincadeiras e Brinquedos ou Dirigente da Igreja; 2. Manejo da Ostra; 3. Modo de Caçar; 4. Modo de Curar (Ofício de Benzedor e Curandeiro); 5. Modo de Fazer Canoa e Varação de Canoa; 6. Modo de Fazer Casa de Paua-pique; 7. Modo de Fazer Roça; 8. Modo de Pescar; 9. Ofício do Artesão; 10. Ofício de Canoeiro; 11. Ofício do Carpinteiro; 12. Ofício de Parteira; 13. Ofício de Capelão; 14. Presidentes do Centro Espírita; 15. Processamento da Cana; 16. Processamento da Mandioca; 17. Processamento do Amendoim; 18. Processamento do Arroz; 19. Processamento do Barro; 20. Processamento do Café; 21. Processamento do Fumo; 22. Processamento do Milho; 23. Puxirão

${ }^{8}$ 1. Rio Ribeira; 2. Rio Pilões; 3. Rio São Pedro; 4. Salto do Abobral; 5. Pedra da Serpente; 6. Barro Branco; 7. Fazenda Caiacanga; 8. Bomba Bombas; 9. Morro da Paca; 10. Roncador; 11. Cotia; 12. Cemitério dos Anjinhos; 13. Sitio do Monjolo; 14. Córregos (da Banana, do Peixe, Grande, da Lage); 15. Toca da Onça; 16. Caminho da Figueira; 17. Sitio Boava; 18. Campo de Futebol e Antigo Casarão; 19. Capovinha; 20. Sítio do Carvão; 21. Caminho dos Pilões; 22. Morro do Chumbo Ivaporunduva; 23. Bocó; 24. Poça; 25. Rodrigues; 26. Córrego Grande; 27. Cemitério atual; 28. Cemitério antigo; 29. Caminho do Pecê (Mandira até a Maré); 30. Rio Boacica (Porto da Maré e Porto do Abrão); 31. Porto do Saco; 32. Porto de Fora; 33. Sambaqui; 34. Cachoeira do Mandira; 35. Trilha do Pindaúva; 36. Morro do Mandira; 37. Serra do Montenegro; 38. Caminho da Serra Acima; 39. Capova dos Veados; 40. Capova do Foge; 41. Capuava do Januário e José Ferro; 42. Rio Peropava; 43. Grota do Morcego; 44. Morro da Bezerra; 45. Guardamó; 46. Caminho e Sítio do Cunha; 47. Caminho do Turvo; 48. Rio Nhunguara; 49. Serra da Laranja Azeda; 50. Rio Pedro Cubas; 51. Pedra Branca; 52. Morro da Olaria; 53. Caminho do Tropeiro; 54. Morro do Cruzeiro; 55. Rio Itacolomi; 56. Cemitério; 57. Caminho do Tropeiro; 58. Serra da Lapinha; 59. Morro da Santana; 60. Cemitério; 61. Caminho da Berta; 62. Rio Pardo; 63. Martinho; 64. As Vargens; 65. Caminho do Morro do Chumbo; 66. Casa de pedra; 67. Morro do Foge; 68. Capoeira do Bode; 69. Cachoeira do Sapatu; 70. Figueira; 71. Remoardo Assombração; 72. Queda do Meu Deus / Capova da Morte; 73. Saltinho; 74. Represa de Pedra; 75. Capova Água Grand. (ISA, 2013, p. 17)
\end{abstract}

escravocrata, ou mesmo de outros eventos ocorridos no passado, que segundo Andrade e Tatto (2013, p. 16) constituem "um conjunto de narrativas que pertencem a um número restrito de pessoas, mas que compõem a trajetória das comunidades negras rurais e a própria história do Vale do Ribeira".

As $29^{9}$ (vinte e nove) Edificações identificadas como bens culturais imateriais para efeitos do Inventário Cultural do Vale do Ribeira, são a última categoria de bens culturais imateriais, segundo a metodologia INRC-IPHAN. Estão associadas às celebrações e formas de expressão, que acontecem majoritariamente nos espaços das igrejas católicas, de grande relevância para a região, com o tombamento da Igreja Nossa Senhora do Rosário dos Homens Pretos, pelo CONDEPHAAT (Conselho de Defesa do Patrimônio Histórico, Arqueológico, Artísitico e Turístico do Governo do Estado de São Paulo) como patrimônio histórico.

A contribuição das Comunidades Quilombolas para o patrimônio cultural brasileiro é incomensurável, confirmada por estudo realizado pela Universidade Federal Fluminense (UFF) em parceria com a Organização das Nações Unidas para a Educação, a Ciência e a Cultura 
(UNESCO), obtendo como resultado o Inventário dos Lugares de Memória do Tráfico Atlântico de Escravos e da História dos Africanos Escravizados no Brasil ${ }^{10}$, do qual afirma que todas as comunidades quilombolas do Brasil são patrimônios imateriais.

Portanto, embora as comunidades quilombolas do Brasil sejam reconhecidas enquanto patrimônios culturais imateriais, tal reconhecimento não verte em ações públicas de proteção e preservação que os abranja integralmente, demandando a continuidade da luta quilombola organizada, através de pressão e controle social junto ao Estado, a fim de garantir efetividade aos seus Direitos Constitucionalmente previstos, seja pela regulamentação do art. 216, § $6^{\circ}$, seja pela desburocratização do processo de tombamento geral.

\subsection{DIREITO DE ACESSO ÀS TERRAS QUILOMBOLAS}

O Direito ao acesso às terras Quilombolas foi positivado no Art. 68 do Ato das Disposições Constitucionais Transitórias, reconhecendo-se a existência das comunidades

\footnotetext{
${ }^{9}$ 1. Igreja de Nossa Senhora Aparecida; 2. Igreja de Nossa Senhora Aparecida; 3. Igreja de Nossa Senhora Aparecida; 4. Igreja de Nossa Senhora Aparecida; 5. Igreja de Nossa Senhora do Rosário dos Homens Pretos; 6. Igreja de Santa Catarina; 7. Igreja de Santa Luzia; 8. Igreja de Santo Antônio; 9. Igreja de São Benedito; 10. Igreja de São José; 11. Igreja de São Bento ou Caiacanga; 12. Igreja de São Miguel Arcanjo; 13. Igreja de São Pedro; 14. Igreja de São Sebastião; 15. Igreja de São Vicente de Paula; 16. Capela em Ruínas; 17. Igreja em Ruínas; 18. Centro Comunitário de Mandira; 19. Centro Comunitário de Morro Seco; 20. Centro Comunitário de Cangume; 21. Centro Comunitário de Praia Grande; 22. Centro Espírita; 23. Casa de Pedra; 24. Salão de Corte e Costura; 25. Ruínas de engenho; 26. Valas de desvio para mineração; 27. Barracão de Palha; 28. Casa de Taipa; Tráficos de Farinha de Mandioca.

${ }^{10}$ Disponível em: 〈http://www.labhoi.uff.br/sites/default/files/inventario_julho_2013.pdf>

quilombolas e a obrigação do Estado em imitir os respectivos títulos de propriedade definitiva relativas às terras ocupadas por quilombolas. O caráter de transitoriedade do dispositivo constitucional, denota a intenção do constituinte originário de exaurir as titulações, tornando inócua a positivação.
}

No entanto, após mais de 30 (trinta) anos desde a promulgação da Constituição Federal de 1988, as titulações de propriedade das terras quilombolas seguem a passos lentos, no total de $7 \%$ dos territórios das comunidades quilombolas, com mais de 1.500 (um mil e quinhentos) processos em andamento, segundo estimativas da Comissão Pró-Índio de São Paulo (CPISP) ${ }^{11}$, demandando cerca de 1.000 (um mil) anos, para a outorga de todos os títulos de propriedade definitiva às comunidades quilombolas, segundo estimativas da Terra de Direitos ${ }^{12}$.

O Art. 68 do ADCT entrou em vigor sem qualquer regulamentação, de modo que a

Revista de de Movimentos Sociais e Conflitos | e-ISSN: 2525-9830 | Encontro Virtual | v. 7 | n. 1 | p. 41-61 | Jan/Jul. 2021. 
titulação das terras quilombolas permaneceu no campo da discricionariedade de cada ente da federação com localidade quilombola. Muitas foram as tentativas de regularização do Art. 68 do ADCT pela via do processo legislativo, todas sem êxito. A iniciativa de unificação das regras e requisitos para a outorga do título, próspera em um primeiro momento, foi a do Decreto n. 3.912, de 10 de setembro de 2001. Posteriormente revogado pelo Decreto 4.887 de 20 de novembro de 2003, que regulamenta o procedimento para identificação, reconhecimento, delimitação, demarcação e titulação das terras quilombolas.

O Decreto n. $4.887 / 2003$ estabelece $14^{13}$ (quatorze) fases até o registro da outorga do título de propriedade definitiva quilombola, norteados pelos princípios da coletividade, da autodefinição, da Territorialidade, da Audiência dos Interessados, da Gratuidade do Processo Administrativo e da Limitação da Propriedade (ABRANTES; KEMPFER e SCALASSARA (2020, p. 15), método que confere segurança jurídica ao ato administrativo, mas revela-se extremamente moroso e custoso.

A morosidade excessiva e alto custo do processo administrativo de titulação da propriedade quilombola, não foi o único óbice encontrado pelas comunidades para o acesso às suas terras. Em 2004, o Partido da Frente Liberal (PFL), atual Democratas (DEM), impetrou a Ação Direta de Inconstitucionalidade (ADI) n. 3239 no Supremo Tribunal Federal (STF),

\footnotetext{
${ }^{11}$ Disponível em: < https://cpisp.org.br/primeira-titulacao-de-terra-quilombola-no-brasil-completa-20-anos/>

12 Disponível em: < https://terradedireitos.org.br/noticias/noticias/no-atual-ritmo-brasil-levara-mil-anos-paratitular-todas-as-comunidades-quilombolas/23023>

13 1. Organização; 2. Impulso; 3. Autodefinição; 4. Inscrição da Autodefinição; 5. Trabalhos de campo; 6. Publicidade dos trabalhos de campo; 7. Notificação de Terceiros Interessados; 5. Prazo para contestação; 9. Consulta aos órgãos competentes; 10. Análise fundiária; 11. Vistoria e avaliação; 12. Outorga do título coletivo; 13. Registro cadastral do imóvel; 14. Registro do título no Cartório de Registro de Imóveis.
}

questionando o Decreto n. 4.887/2003. O Poder Judiciário também se mostrou excessivamente moroso para solucionar a questão, concluindo o julgamento da ação somente em 2018, com a declaração de constitucionalidade do decreto.

A pacificação do entendimento do Supremo Tribunal Federal pela constitucionalidade do decreto n. 4.887/2003, não foi capaz de conferir efetividade ao Art. 68 do ADCT, na medida em que, mesmo após a decisão, as titulações continuam em ritmo demasiadamente lento, e inclusive apresentaram queda de 4,38\% no percentual de execução orçamentária do empenho liquidado pelo Instituto Nacional de Colonização e Reforma Agrária (INCRA) em 2018, em relação ao ano anterior (2017), seguido de nova queda de 2,95\% em 2019, conforme dados 
apresentados por ABRANTES; KEMPFER e SCALASSARA (2020, p. 22), no II Encontro Virtual do CONPEDI.

A Luta Quilombola por acesso às suas terras continua, haja vista que a situação política e orçamentária para efetividade desse Direito permanece inalterada, demandando a atuação das comunidades quilombolas nos espaços públicos institucionais de denúncia a violação de Direitos, como a Comissão Interamericana de Direitos Humanos ${ }^{14}$ sobre a situação dos direitos humanos das comunidades quilombolas no Brasil, ainda em espaços institucionais judiciais, para apresentação de demandas relativas à morosidade excessiva do processo administrativo de titulação das terras quilombolas, de inviabilização de acesso a moradia digna, e de intributabilidade de suas terras.

\section{DA LUTA QUILOMBOLA POR MEIO DAS INSTITUIÇÕES JUDICIAIS PARA EFETIVIDADE DE SEUS DIREITOS}

As Comunidades Quilombolas são obrigadas a resistir e lutar por seus Direitos, para a garantia de sobrevivência e perpetuação. A efetividade de seus Direitos caminha em direção da judicialização de suas demandas. Para esta pesquisa, aponta-se os casos das comunidades de Charco (Eldorado-SP), Chácara das Rosas (Canoas-RS) e Alpes (Porto Alegre-RS), a título exemplificativo, uma vez que tais casos são expoentes das questões afetas à propriedade quilombola, comumente reproduzidas em âmbito nacional.

A Comunidade Quilombola de Pedro Cubas, na cidade de Eldorado-SP, instaurou o processo administrativo de titulação de suas terras em 2004, com a conclusão dos trabalhos de campo somente em 2011. O processo administrativo n. 54190.001.696/2005-73. permaneceu

\footnotetext{
${ }^{14}$ Disponível em: < https://terradedireitos.org.br/noticias/noticias/organizacoes-denunciam-racismo-eviolacao-de-direitos-quilombolas-para-comissao-interamericana/23022>
}

paralisado após a fase de conclusão dos trabalhos de campo, levando a comunidade, que aguardava pela titulação há quase 10 (dez) anos, a judicializar sua demanda, acionando o Ministério Público Federal em 2013, para distribuição da Ação Civil Pública n. 000440591.2013.4.01.3902.

O magistrado da $1^{\text {a }}$ Vara Federal de Registro prolatou sentença favorável à comunidade quilombola de Pedro Cubas de Cima, em 22 de fevereiro de 2016, obrigando o 
INCRA a concluir e publicar os trabalhos de campo no prazo de 6 (seis) meses, para dar continuidade ao processo administrativo respeitando a duração razoável do processo:

(...) Ainda que não haja no Decreto $n^{\circ} 4.887 / 2003$ prazo para a confecção do Relatório Técnico de Identificação e Demarcação - RTID, dada a sua complexidade, não é razoável uma demora de aproximadamente 11 (onze) anos para sua conclusão.

(...)

Tampouco se aplica à hipótese a fórmula da reserva do possível que não pode ser invocada para legitimar o injusto inadimplemento de deveres estatais constitucionalmente impostos. Aliás, a demora na elaboração do Relatório Técnico de Identificação e Demarcação - RTID não se justifica pelas alegações de acúmulo de processos administrativos ou carência de pessoal, que podem, quando muito, gerar algum atraso, persistindo, contudo, o direito ao término do procedimento em tempo razoável.

Sobre o tema a Constituição Federal, em seu art. 50, LXXVIII, dispõe que "a todos, no âmbito judicial e administrativo, são assegurados a razoável duração do processo e os meios que garantam a celeridade de sua tramitação". Em outras palavras, a Constituição Federal garante a todos no âmbito judicial ou administrativo a razoável duração do processo. Desse modo, indevida a demora excessiva/injustificada no andamento/conclusão do procedimento administrativo, que não deve se estender injustificadamente, devendo terminar em prazo razoável, principalmente porque a indefinição acerca da delimitação da área em questão gera insegurança para a comunidade quilombola.

Diante desse quadro fático em que constatada conduta ilegal e abusiva na condução do procedimento administrativo em questão, é razoável determinação para que a Administração Pública conclua a elaboração do Relatório Técnico de Identificação e Demarcação - RTID e o publique no prazo de 6 (seis) meses, respeitando posteriormente o Poder Público os prazo estabelecidos no Decreto $\mathrm{n}^{\circ}$ 4.887/2003 e, quando não determinados, aqueles estabelecidos pela Lei $n^{\circ} 9.784 / 199$, que regula $o$ processo administrativo no âmbito federal. (FERREIRA LOPES, LETICIA DEA BANKS. Juíza Federal. Sentença, 2016, p. 7-8 $)^{15}$

A comunidade quilombola de Pedro Cubas foi titulada parcialmente, pouco tempo depois, em 08 de novembro de 2016, obtendo a efetividade de seu direito de acesso à terra, pela via judiciária, ainda que parcialmente. A conquista da comunidade quilombola de Pedro Cubas sinaliza o caminho para efetividade e duração razoável do processo administrativo de titulação das terras, às demais comunidades quilombolas do País.

${ }^{15}$ Disponivel em:<https://drive.google.com/file/d/OB9jdAQchOUNcektuY2xzczhHWGc/view>

A titulação das terras quilombolas é medida excepcional no Brasil, e poucas comunidades foram tituladas, parcial ou integralmente. A comunidade dos Alpes tem seu processo administrativo em fase relativamente avançada, com decreto de desapropriação em 02 de agosto de 2016. Assim, a comunidade submeteu projeto de acesso à moradia digna à Caixa 
Econômica Federal, gestora do Programa Minha Casa, Minha Vida, através do subprograma "Entidades", aprovado pela resolução n. 21/2016 do Fundo de Desenvolvimento Social.

Contudo, mesmo após a habilitação da proposta, a construção do empreendimento habitacional na comunidade quilombola dos Alpes foi considerada inviável pela operadora do programa, acionada pela via judicial pelos quilombolas lesados, mediante representação processual do Ministério Público Federal, na Ação Civil Pública n. 504181635.2018.4.04.7100. A ação foi julgada procedente em primeira instância e confirmada pela $3^{\mathrm{a}}$ Turma do Tribunal Regional Federal da $4^{\mathrm{a}}$ Região:

CIVIL. ADMINISTRATIVO. CONTRATO DE MÚTUO PARA CONSTRUÇÃO DE IMÓVEIS RESIDENCIAIS. COMUNIDADE QUILOMBOLA. PMCMV. FDS. FIANÇA SOLIDÁRIA. 1. Em que pesem asgarantias (hipoteca e alienação fiduciária) previstas na norma infralegal serem incompatíveis com o título de propriedade da Associação do Quilombo dos Alpes, a parte ré deveria ter oferecido opção de outra modalidade de garantia, sob pena de obstar o próprio acesso ao financiamento público de moradia às comunidades quilombolas, o que implicaria em discriminação indevida de minoria cujo vulnerabilidade socioeconômica o ordenamento pátrio busca justamente reduzir. Assim, é possível, sem prejuízo à contraparte, conceder-se o financiamento mediante a modalidade "garantia solidária", a ser prestada por cada um dos moradores postulantes ao mútuo. 2. A determinação para que a CEF dê início à construção do empreendimento no prazo de 90 (noventa) dias, independentemente da problemática que envolve a liberação dos recursos necessários junto ao FDS, é providência excepcional frente à injusta suspensão pelas rés do empreendimento habitacional da Comunidade Quilombola dos Alpes, e com o escopo de afastar a grave infringência ao direito constitucional à moradia do aludido grupo étnico. (TRF4, AC 5041816-35.2018.4.04.7100, TERCEIRA TURMA, Relator ROGERIO FAVRETO, juntado aos autos em 07/08/2020)

Diante da lacuna legislativa, os desembargadores da $3^{\text {a }}$ Turma do Tribunal Regional Federal da $4^{\mathrm{a}}$ Região diante da lacuna legislativa na modalidade de garantia compatível com as terras quilombolas, acordaram em substituir a garantia prevista fiduciária, pela modalidade de garantia solidária, a ser prestada por um dos membros associados da comunidade quilombola dos Alpes, viabilizando a celebração do contrato de financiamento habitacional, conferindo efetividade de acesso à moradia. $\mathrm{O}$ precedente sinaliza às demais comunidades quilombolas a possibilidade de adesão ao financiamento popular na modalidade de garantia solidária.

Por fim, o caso da comunidade quilombola chácara das rosas diz respeito à comunidade já titulada integralmente e já contemplada por programa habitacional de acesso à moradia digna, demonstrando outro patamar de problemas que podem ser enfrentados por 
outras comunidades quilombolas: a tributação das terras em áreas urbanas. A legislação Federal prevê a isenção da cobrança de ITR nas comunidades rurais, mas ainda não há nenhuma previsão expressa constitucionalmente acerca da imunidade tributária das terras quilombolas, para abranger todas as comunidades, em qualquer localidade.

Deste modo, as comunidades quilombolas localizadas em zonas urbanas, ficam à mercê da discricionariedade do ente federativo municipal, para legislar sobre a isenção da cobrança do IPTU, e mesmo com a participação popular da associação quilombola nos debates públicos com o legislativo municipal, indicando a necessidade da intributabilidade de suas terras, não obtiveram êxito.

A solução encontrada pela comunidade quilombola Chácara das Rosas deu-se através do espaço institucional judiciário, através do Ministério Público Federal na Ação Civil Pública n. 5005268-43.2016.4.04.7112 junto à Justiça Federal do Rio Grande do Sul. A Ação Civil foi distribuída com objetivo de obter a declaração de intributabilidade do território da Chácara das Rosas, do Poder Judiciário, por consequência a inexigibilidade das dívidas pretéritas e futuras em relação ao IPTU, bem como da contribuição sobre a iluminação pública e outras taxas.

A demanda da comunidade quilombola Chácara das Rosas foi atendida, julgada parcialmente procedente, com o reconhecimento do direito da intributabilidade do território, nos seguintes termos:

(...) A matéria relativa ao direito das comunidades quilombolas as terras que tradicionalmente ocupavam tem assento constitucional nos artigos 68 do Ato das Disposições Constitucionais transitórias (ADCT) e 215 e 216 do corpo permanente da Carta Básica.

(...)

A análise sistemática desses dispositivos permite inferir que, para além de se atribuir aos remanescentes dos quilombos a propriedade das terras que ocupavam, declarouse que tais imóveis constituem patrimônio cultural brasileiro exatamente por serem portadores de referência à ação e à memória dos diferentes grupos formadores da sociedade brasileira, sendo essa a razão porque ficaram "tombados todos os sítios detentores de reminiscências dos antigos quilombos".

Trata-se do reconhecimento de um direito fundamental de terceira geração, jungido e imbricado à proteção de uma realidade étnico-cultural que, por pertencer a uma minoria vulnerável, mereceu especial proteção estatal. Evidencia-se que o objetivo visado pelo legislador constituinte não foi o de conferir um direito individual de propriedade tal como ordinariamente reconhecido na legislação civil, mas o de criar um instituto que, ao mesmo tempo em que protege os modos de criar, fazer e viver dessa minoria étnica e cultural, permite, ao conferir a titularidade dos imóveis que ocupavam à coletividade e não ao indivíduo isolado, que essas comunidades tenham garantidas a sua reprodução física, social, econômico e cultural $\left(\operatorname{art} .2^{\circ} \S 2^{\circ}\right.$ do Decreto $\left.n^{\circ} .4 .887 / 2003\right)$.

Revista de de Movimentos Sociais e Conflitos | e-ISSN: 2525-9830 | Encontro Virtual | v. 7 | n. 1 | p. $41-61$ | Jan/Jul. 2021. 


\section{$(\ldots)$}

Assim, o pleito de imunidade tributária merece prosperar, com fundamento no art. 150, VI, 'c', da Constituição Federal c/c art. 14 do CTN. (...)

O precedente conquistado pela comunidade quilombola Chácara das Rosas denuncia a ausência de previsão constitucional expressa acerca da intributabilidade das terras quilombolas. E também expõe alternativa da instituição judiciária para efetividade de seus Direitos, às demais comunidades quilombolas localizadas em zonas urbanas, reforçando e confirmando o caminho a ser trilhado na constante luta quilombola por garantia e efetividade de Direitos.

\section{CONCLUSÃO}

A organização das Comunidades Quilombolas em Associações e a criação da representação nacional das Comunidades Quilombolas pela Coordenação Nacional de Articulação das Comunidades Negras Rurais Quilombolas - CONAQ, são movimentos sociais e políticos fundamentais na luta quilombola junto aos espaços públicos institucionais, para buscar efetividade práticas de suas reivindicações.

Os Espaços Públicos, defendidos pelo ideário republicano, possibilitaram a positivação dos Direitos Quilombolas relativos à proteção e preservação cultural, e ao acesso e titulação das terras, durante o processo de redemocratização do Brasil, através de articulação fundamental do movimento negro junto à Assembleia Nacional Constituinte.

Contudo, o cenário do acesso aos Direitos Quilombolas, denota a falta de efetividade dos textos normativos, com números discrepantes em entre às comunidades quilombolas existentes no Brasil, e as comunidades que conseguiram acessar o direito ao tombamento, à proteção, preservação e difusão cultural, e principalmente entre as comunidades que conseguiram o registro da outorga do título de propriedade definitiva.

O território quilombola é local de memória, resistência, de rico acervo cultural, mas também de organização política, para articulação de suas demandas junto aos espaços públicos institucionais, especificamente junto ao Judiciário, onde cria precedentes fundamentais para continuidade da luta pelo acesso à terra.

A mobilização quilombola junto ao Poder Judiciário em relação à duração razoável do processo administrativo de titulação das terras quilombolas, indica a possibilidade de eventual e futura demanda por agilidade nos processos de tombamento em andamento, ainda em fase de 
instrução. As Comunidades Quilombolas também encontram nas instituições judiciais, a possibilidade de impetrar mandado de injunção junto ao Supremo Tribunal Federal, para pressioná-lo a criar soluções para as omissões legislativas, na titulação de propriedade cultural do Instituto do Patrimônio Histórico e Artístico Nacional - IPHAN.

\section{REFERÊNCIAS BIBLIOGRÁFICAS:}

ALBUQUERQUE, Wlamyra R. de Uma história do negro no Brasil. Salvador: Centro de Estudos Afro-Orientais; Brasília: Fundação Cultural Palmares, 2006.

ANDRADE, Anna Maria; TATTO, Nilto. Inventário cultural de quilombos do Vale do Ribeira. São Paulo: Instituto Socioambiental, 2013.

ARENDT, Hannah. O Que é Política? 3ª ed. Rio de Janeiro: Bertrand Brasil, 2002.

BALLESTER. Candice dos Santos; Instituto do Patrimônio Histórico e Artístico Nacional. Dossiê de Candidatura da Serra da Barriga, Parte Mais Alcantilada - Quilombo dos Palmares a Patrimônio Cultural do MERCOSUL / [et al.]; Marcelo Brito, coordenador ; Candice dos Santos Ballester, Greciene Lopes dos Santos, organizadoras; Aruã Lima [et al.], colaboradores; Fidelity Translations LTDA, tradutor. - São Carlos : Editora Cubo, 2017.

BERLIN, Isaiah. Dois conceitos de liberdade. In.: BERLIN, Isaiah. Estudos sobre a humanidade: uma antologia de ensaios. Tradução Rosaura Eichenberg. São Paulo: Companhia das Letras, 2002.

BRASIL. Constituição Política do Imperio do Brazil (DE 25 DE MARÇO DE 1824). Disponível em: <http://www.planalto.gov.br/ccivil_03/constituicao/constituicao24.htm> Acesso em 06 set 2020

. Lei n. 3.353 de maio de 1888 (Lei Áurea). Declara extinta a escravidão no Brasil. Disponível em: http://www.planalto.gov.br/ccivil_03/leis/lim/LIM3353.htm. Acesso em 10 out. 2020.

. Constituição da República dos Estados Unidos do Brasil (DE 24 DE FEVEREIRO DE 1891). Disponível em: <http://www.planalto.gov.br/ccivil_03/constituicao/constituicao91.htm> Acesso em 15 fev 2021.

. Constituição da República Federativa do Brasil, de 05 de outuro de 1988. Disponível em: <http://www.planalto.gov.br/ccivil_03/constituicao/constituicao.htm> Acesso em 06 set 2020

CHAUÍ, Marilena. O Que é Política? In: NOVAES, Adauto. O Esquecimento da Política. Rio de Janeiro: Agir, 2007 (p.27 a 53).

CONAQ. Regimento Interno da Coordenação Nacional de Articulação das Comunidades Negras Rurais Quilombolas. Brasília. 2013.

CONSTANT, Benjamin. Da liberdade dos antigos comparada à dos modernos. In.: MONTEIRO, João Paulo e ou. Filosofia Política 2. Porto Alegre: L\&amp;PM Editores (UNICAMP/UFRGS - com apoio do CNPQ), 1985. 
FREITAS, Augusto Teixeira de. Consolidação das Leis Civis. Ed. Fac-sim. Brasília: Senado Federal, Conselho Editorial, 2003.

HESSEN, JOHANNES. Filosofia dos Valores. Tradução e Prefácio do Prof. L. Cabral de Moncada. Coleção Stvdivm. 4 ed. Editora Armênio Amado, 1964.

IPHAN. Processo $n^{\circ}$ 1.410-T-98 [Referente ao tombamento da Área conhecida como "Ivaporanduva", ocupada por comunidade remanescente de quilombo (...), Eldorado/SP].

Processo $n^{o}$ 1.069-T-82 [Referente ao tombamento da Serra da Barriga (Quilombo dos Palmares), União dos Palmares/AL].

. Sistema Agrícola Tradicional das Comunidades Quilombolas do Vale do Ribeira. Disponível em: <http://portal.iphan.gov.br/pagina/detalhes/1944> Acesso em 15 abr 2021.

Difusão dos Bens Culturais em Quilombos do Vale do Ribeira. Disponível em: <http://portal.iphan.gov.br/pagina/detalhes/1009/> Acesso em 15 abr 2021.

ISA. Instituto Socioambiental. Turismo de Base Comunitária. Circuito Quilombola. Disponível em: < https://www.socioambiental.org/sites/blog.socioambiental.org/files/publicacoes/livreto.pdf> Acesso em 15 abr 2021.

ITESP. Ações. Desenvolvimento das Comunidades. Disponível em: <http://www.itesp.sp.gov.br/br/info/acoes/comunidades.aspx> Acesso em 15 abr 2021.

OLIVEIRA, Laiana Lannes de. A Frente Negra Brasileira: Política e Questão Racial nos anos 1930. 2002. Dissertação (Mestrado em História Política) - Instituto de Filosofia e Ciências Sociais, Universidade do Estado do Rio de Janeiro.

PETTIT, Philip. Republicanismo: una teoria sobre la libertad y el gobierno. Tradução para o espanhol: Toni Demènech. Barcelona: Paidós, 1999.

PINTO, Ricardo Leite. Uma introdução ao neo-republicanismo. Análise Social, vol.. XXXVI (158-159), 2001, 461-485.

RAMOS, César Augusto. O liberalismo político e seus críticos. Crítica: Revista de Filosofia. Londrina: Universidade Estadual de Londrina. Vol. 10, número 32, p. 229-264, out. 2005.

RIBEIRO, Renato Janine. A República. São Paulo: Publifolha, 2005.

TRECCANI, Girolamo Domenico. Terras de Quilombo: caminhos e entraves do processo de titulação. Belém: Secretaria Executiva de Justiça. Programa Raízes, 2006.

VAZ, Beatriz Accioly. Quilombos e Patrimônio Cultural: reflexões sobre direitos e práticas no campo do patrimônio. 2014. 132 f. Dissertação (Mestrado em Preservação do Patrimônio Cultural) - Iphan, Rio de Janeiro, 2014

VILANOVA, Lourival. Causalidade e Relação no Direito. 2. ed. São Paulo: Saraiva, 1989. 